\title{
UM CASO DE LUES DO BAÇO
}

\author{
Observação do Serviço do Dr. Eduardo Monteiro - Polyclinica \\ de São Paulo
}

ROBERTO PLACCO

(DOUTORANDO)

Compulsando a litteratura medica, no tocante ás esplenomegalias raras, vimos ahi enquadrada a syphilitica. Esta razão e, mais talvez, o factor bôa vontade, traze-nos hoje ao Departamento Scientifico do nosso gremio "Oswaldo Cruz", para relatar um caso de lues terciaria do baço. Serão alguns minutos de entretenimento util, em que, á luz de nossos conhecimentos, poderemos exercitar as possibilidades propedeuticas que nos competem. Em outra opportunidade, dleste mesmo lugar, vos disse do ca1acter eminentemente clinico que damos ás nossas observações. Entretanto, procurámos circumđar o caso em apreço, dos exames complementares mais indispensaveis á elucidação.do diagnostico, uma vez que, as interpretações baseadas em manobras puramente clinicas, deixariam duvidas a respeito desta questão.

Notae comtudo, que não cogitamos aqui, das esplenomegalias, avantajadas ou discretas, que a invasão septicemica do periodo secundario provoca. Em taes occurrencias, o baço se entumece, reagindo ao elemento extranho, como faz em qualquer eventualidade semelhante, justificando plenamente assim a sua funcção lymphoide. Fôra isso e não estariamos occupando a vossa preciosa attenção em assumpto tão falto de interesse, dada sua extrema frequencia.

Feita esta resalva passemos ao caso:

Aos 7 dias do mez de março do corrente anno, ingressa na Folyclinica de São Paulo, Serviço do Dr. Eduardo Monteiro, F. S.; branca, casada, brasileira, com 50 annos de idade, procedente de Leme - Estado de São Paulo - afim de obter consulta e therapeutica para seus padecimentos, já de longa data. 
QUEIXA: Syntheticamente, a narração de sua queixa limitasc ao intenso gráu de depauperamento e, sobretudo, dôres generalizadas pelo abdomen, com predominancia do lado esquerdo, na regiāo do hyppocondrio e flanco correspondentes.

ANAMNESE: Esmiuçada a anamnése, eis o que de importante se deprehende. Para o lado dos commemorativos familiares nada interessa, relativamente á sua molestia. Paes fallecidos de morte natural em idades avançadas. Emquanto vivos, sempre primaram pela robustez. De nove irmãos que teve, quatro são mortos, os cinco restantes são sadios, a excepção de um que sempre foi doente. Não ha abortos em sua familia. De si mesma, até suas nupcias, realizadas ha oito annos atraz, nenhuma a normalidade séria acommetteu sua integridade organica, excepto infecções - sarampo, coqueluche, etc. - mais frequentes da idade infantil e destituidas le sequellas. Pubere, com o advento de sua menarca, aos 14 annos, de então para cá, até a menopausa occorricla ha dois annos, os catamenios succederam-se regularmente. Vejamos, em seguida, o que the aconteceu após o casamento. Dois annos passaram-se, durante os quaes nenhum facto morbido lhe attingiu que mereça ser narrado, quando, abruptamente, appareceu-lhe ao nivel dos genitaes externos, um tumor endurecido e ulcerado. Este tumor, após algum tempo de evolução mais ou menos benigna, desáppareceu expontaneamente. Nesse interim, começou sentir dôres pelo corpo, cephaléa intensa, principalmente nocturna, mal estar geral, febre, ancias de vomito, anorexia e diaphrose accentuada. Taes symptomas duraram por uma longa dezena de mezes. A paciente não procurou soccorro medico algum, contentando-se com a therapeutica caseira. Ora, este estado de coisas perdurou, até o apparecimento de outros dois tumores tambem endurecidos e que posteriormente se ulceraram. A localização delles se fez: um na face anterior, extremidade proximal do braço esquerdo, e outro, na face interna, parte alta da coxa, tambem do lado esquerdo. Assignale-se de passagem, que a inspecção destes dois pontos de referencia mostra, respectivamente, duas cicatrizes, nitidamente estrelladas e caracteristicas das gommas lueticas que ahi se localizaram. Contemporaneamente aos tumores, surgiu-lhe tambem na nucosa nasal, uma ulceração extremamente incommodativa. $O$ advento destes phenomenos, alliado ás perturbações digestivas e symptomas abciominaes do momento, motivaram a sua consulta na Polyclinica. A paciente refere ainda, que engravidou por duas vezes, obtendo como resultado dois abortos expontaneos. Durante o ultimo periodo gravidico, occorreram-lhe colicas abdominaes violentas. Nesta occasião, é-lhe diagnosticada appendicite aguda, conforme declarou, e, por esse motivo foi operada, havendo o ci- 
rurgião extrahido o appendice. Em verdade, no hemi-abdomen direito, região da fossa illiaca, nota-se uma longa cicatriz operatoria. Finalmente, ha tres annos atraz, começaram as dôres abdominaes nas regióes do hyppocondrio e flanco esquerdos. Concomitantemente emmagrecimento visivel, intensa sensação de fraqueza, prisão de ventre alternante com diarrhéas, etc. Neste estado, ingressou na Polyclinica conforme já referimos.

Vejamos a seguir o:

\section{EXAME CLINICO}

Inspecção geral: Individuo do sexo feminino, emmagrecida, anemiada e pertencendo ao typo morphologico longilineo. Os ganglios clas regiões accessiveis ao tacteio, não estão enfartados. Mucosas visiveis empallidecidas, dentes mal conservados. No terço superior, face anterior do braço esquerdo, e, face interna, quarto superior da coxa tambem esquerda, notam-se as duas cicatrizes estrelladas de que já nos occupamos mais atraz. Quasi toda a face anterior do thorax e bôa parte do abdomen - hyppocondrio direito - acham-se tomados de immensa cicatriz, em virtude de uma queimadura, da qual foi victima por um accidente involuntario. Assignale-se, por igual, a já citada cicatriz operatoria que existe no abdomen, fossa illiaca direita. O thermometro, não tem revelado febre, nas tomadas de temperatura que effectuámos. Entretanto, a enferma accusou febre, em opportunidades anteriores ao nosso exame. Esta febre, informou-nos ella, foi ligeira e de typo irregular.

Thorax: O exame clinico deste departamento organico, quer para o lado do coração, quer para o dos pulmões, não offerece signaes reveladores de anormalidades pathologicas. Seria, então, fastidioso e pouco util, para o nosso caso, enumerar os phenomenos physiologicos ahi presentes, pois que fartamente os conheceis.

Abdomen - Inspecção: Á simples inspecção, nota-se abahúlamento do hyppocondrio e flanco esquerdos.

Apalpação: Effectuada esta, methodicamente, revelou-nos um baço muito augmentado de volume, invadindo a cicatriz umbilical, ultrapassando-a ligeiramente, e assenhoreando-se de bôa parte da região opposta a esse nivel.

O tacteio mostrou-nos mais: Que o baço apresenta uma consistencia firme, sua superficie é lisa, pouco doloroso e, finalmente, acompanha com difficuldadie as excursões respiratorias.

Não conseguimos apalpar as incisuras caracteristicas da viscera, provavelmente devido á grande tensão intra-abdominal. En- 
tretanto, julgámos sentir a chanfradura assignalada no eschema abaixo, e, que a percussão mais nitidamente autorizou evidenciar.

Percussão: A percussão, nos permittiu verificar uma área de massicez, com as seguintes referencias :

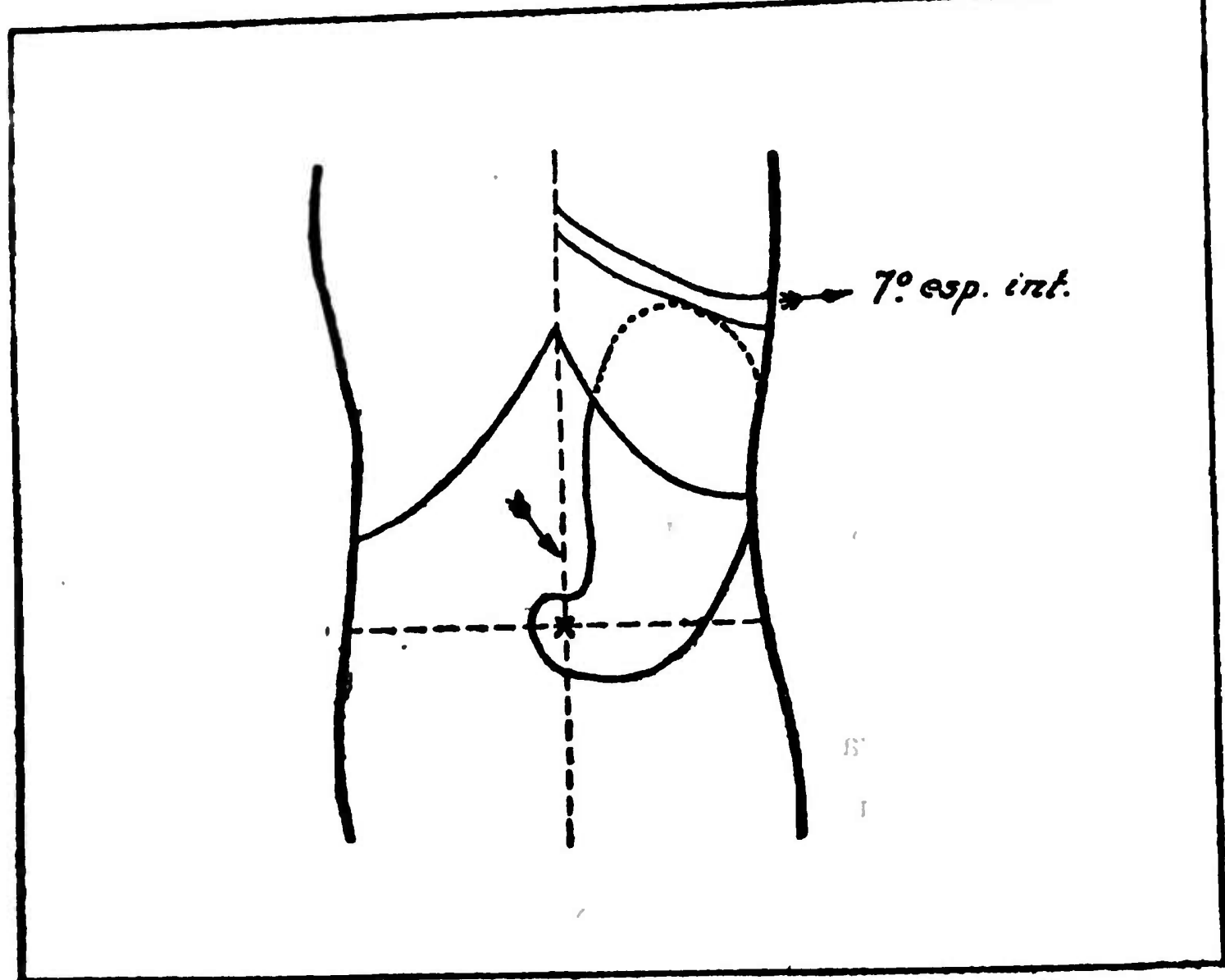

Eschêma da fórma e dimensões do baço, e que a percussão nos permittiu delimitar

Superiormente, attinge o setimo espaço inter-costal ; em baixo, ultrapassa a cicatriz umbilical de uns dois centimetros approximadamente; do lado interno, a linha de massicez descreve uma curva, vindo de cima para baixo, semelhante ao bordo cortante de uma lamina de foice, com a concavidade voltada para a direita $\epsilon$ para o alto. Percute-se o limite extremo de massicez interna, a tres centimetros para a direita da linha mediana e ao nivel do umbigo.

A auscultação da região esplenica, dentro dos limites que assignalámos, não offerece nenhum signal auditivo de valor.

Figado: O figado permanece dentro de seus limites anathomicos normaes.

Espaço de Traube: O espaço de Traube apresenta-se inteiramente massiço. 
As restantes regiões do abdomen nada revelam, a não ser um tympanismo pouco exaggerado das alças intestinaes distendidas, indicando meteorismo.

Systhema nervoso: Relativamente ao systhema nervoso, todos os signaes clinicos'accessiveis, militam em favor de sua integridade funccional.

Exame Gynecologico: Solicitámos um exame gynecologico, que foi gentilmente praticado no respectivo serviço da Polyclinica, com o seguinte resultado: Diagnostico - Leucoplasia vulvar incipiente - Estenose atrophica senil da vagina.

Visto o exame clinico passemos ás:

\section{PROVAS COMPLEMENTARES}

A 7 de março do corrente anno, pesquiza de parasitos no sangue que resultou negativa.

Á 9 do mesmo mez, R. W. - fortemente positiva ( ++++ ).

Á 12, pesquiza de hematozoarios - negativa.

A 3 de abril e, á 5 do mesmo mez - Contagem dos elementos figurados do sangue e dosagem da hemoglobina: - Resultado:

Globulos vermelhos ....... 3.000 .000 p/ mm3.

Globulos brancos ......... $4.400 \mathrm{p} / \mathrm{mm} 3$.

1) monocytos $\left\{\begin{array}{l}\text { linfocytos } \ldots \ldots \ldots \ldots \ldots \ldots \ldots \ldots \\ \text { grandes mononucleares } \ldots \ldots \ldots \ldots\end{array} \quad 9,0 \%\right.$

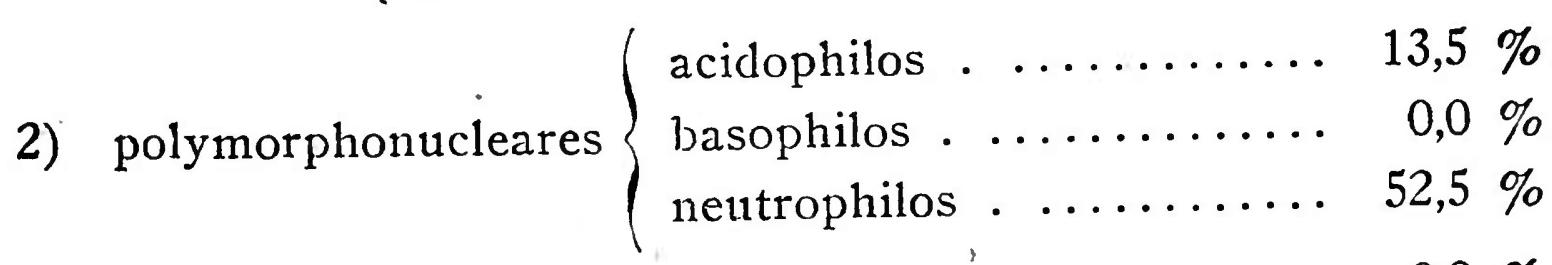

3) hemogramma de Schilling $\left\{\begin{array}{lrr}\text { myelocytos . ......... } & 0,0 \% \\ \text { fórmas jovens ....... } & 2,8 \% \\ \text { fórmas em ferradura .. } & 2,0 \% \\ \text { fórmas segmentadas ... } & 95,2 \%\end{array}\right.$

A 4 de abril, exame completo de urina. - Resultado:

Côr: amarello escura - cheiro putrido - aspecto turvo deposito regular - densidade a $15^{\circ}$ - 1010,1 - Reacção ao tornassol - acida.

Exame do sedimento: Descamações superficiaes das ultimas vias do apo. genito-urinario, alguns leucocytos (1 a 2 por campo), alguns crystaes de acido urico, algumas granulações de urato amorpho e bacterias. 


\section{ELEMENTOS NORMAES}

(Exame dosimetrico)
Vol. - nas 24 horas $1.500 \mathrm{cc}$
Vol. - recebido $1.500 \mathrm{cc}$

\begin{tabular}{|c|c|c|}
\hline Elementos & Em 24 hs. & Por litro \\
\hline 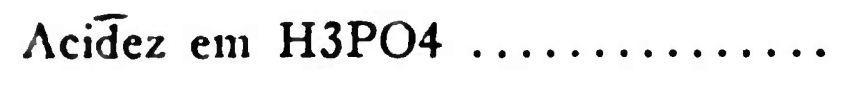 & & 0,48 \\
\hline Ammoniaco . ..... & 0,66 & 0,44 \\
\hline Uréa . ........... & 9,0 & 6,0 \\
\hline Azoto ammoniacal ...... & 0,54 & 0,36 \\
\hline Azoto uréa & 4,18 & 2,79 \\
\hline Phosphatos em P2O5 ... & 1,02 & 0,68 \\
\hline Chloretos em $\mathrm{NaCl} \ldots \ldots \ldots \ldots$ & 14,91 & 9,94 \\
\hline Acido urico & 0,33 & 0,22 \\
\hline
\end{tabular}

Relações urologicas

Acido phosphorico

Azoto ammoniacal

Chloretos Uréa Az. uréa + Az. ammoniacal $11,4 \%$ Acido urico Uréa $165,6 \%$ Uréa $3,6 \%$ ELEMENTOS ANORMAES

Albumina (Exame qualitativo)

Glycose. ausencia Acetona

Acido diacetico 
Á 22 de junho, exame de fezes com enriquecimento pelo methodo de Willis, que resultou negativo.

Até este ponto, todos os exames praticados foram por intermedio da Polyclinica e trazem a assignatura do Dr. Eduardo Vaz, director do laboratorio de analyses do Instituto Pinheiros. Os exames que serão relatados daqui por diante foram, por commodidade, praticados na Santa Casa de São Paulo, pelo nosso collega e amigo doutorando Pedro Paulo Corrêa, que nos favoreceu sobremaneira com sua costumada gentileza. São elles os seguintes:

Reacção de Weinberg, ou do desvio cilo complemento a qual resultou negativa (26-5-34). Nova pesquiza de hematozoarios negativa. Prova da tuberculina ou reacção de Mantoux - tambem negativa. A tuberculina desta prova foi-nos bondosamente cedida pelo Dr. Oscar Monteiro de Barros a quem muito agradecemos (23-5-34).

Finalmente novo exame de sangue - quadro hematologico para controlle do tratamento, com o seguinte resultado:

Erytrocytos

Leucocytos

Dosagem da hemoglobina ...............

Valor glcbular
$3.880 .000 \mathrm{p} / \mathrm{mm} 3$

$6.950 \mathrm{p} / \mathrm{mm} 3$

$60 \%$

0,91

\section{CURVA LEUCOCYTARIA}

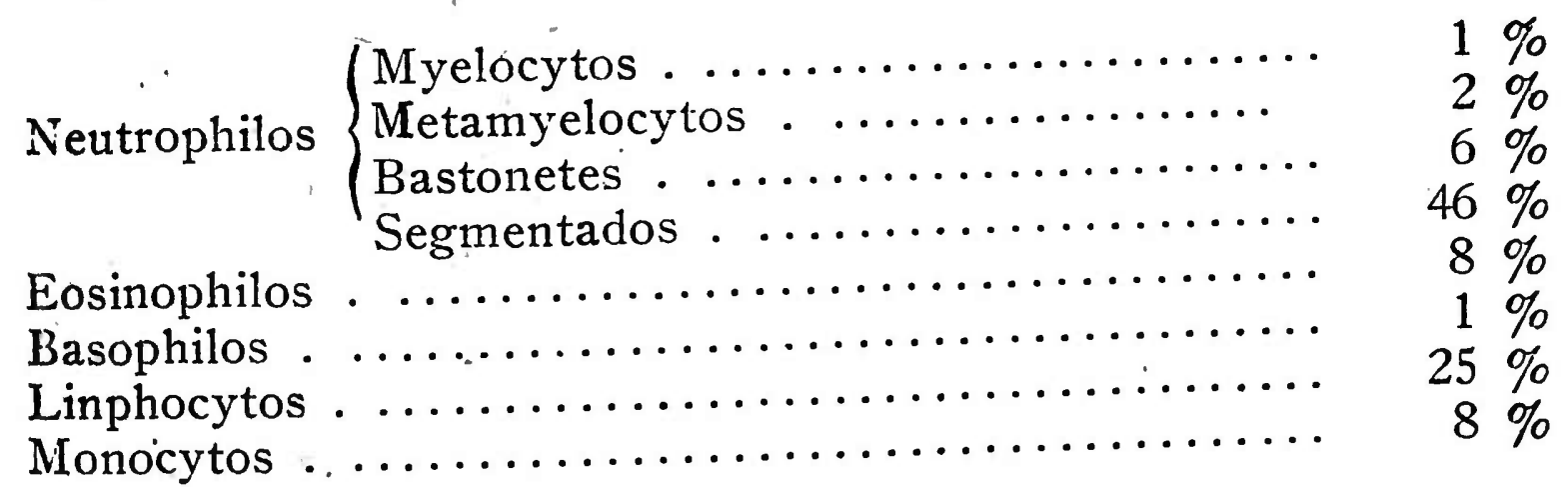

Poderiamos ter ainda puncionado o baço, para pesquizar directamente ao microscopio os treponemas, mas, não ousamos, em vista dos riscos a que estaria sujeita a paciente - ruptura do parenchima, hemorrhagia interna, disseminação do processo morbido ás adjacencias, etc.

\section{Diagnostico}

Baseados em todos estes exames, na observação clinica e, principalmente, na evolução therapentica do caso, conforme veremos mais adiante, estabelecemos o diagnostico, de accôrdo com o nosso mestre Dr. Eduardo Monteiro, de lues terciaria do baço. 


\section{Therapeutica e evolução}

Iniciámos o tratamento da paciente a 7 de março. Usámos a a-urciaçāo iodo mais bismutho, durante um mez e meio, sob a fórma de "xy-iodeto de bismutho em empoullas de 2 cc. de 0,10 de oxy-iodeto. Durante esse tempo de tratamento, empregámos 20 cmpoullas (duas grammas) da medicação, em injecções intramusculares e em dias alternados. $\mathrm{O}$ resultado foi o seguinte:

Na primeira semana, houve ligeira regressão do baço e visireis melhoras do estado geral da enferma. Na segunda semana, manifestou-se uma exacerbação do processo pathologico. Assim foi que o baço se nos revelou mais endurecido, mais volumoso. As dóres abdominaes accentuaram-se ainda com maior. violencia, e tudo nos indicava que o estado geral da paciente peorára. Embora isso, não cessámos o tratamento. Attribuimos os phenomenos adventicios á propria acção dos agentes medicamentosos sobre os germes, provocando estas reacções que, em ultima analyse, eram salutares. Isto perdurou ainda por alguns dias, quando a doente soffreu uma infeç̧ão grippal aguda, com reacção febril intensa. Cuidavamos, concomitantemente, desta intercorrencia pathologica, quando a paciente, por sua propria conta, resolveu internarse na Santa Casa de São Paulo. Permaneceu ahi 15 dias. Contounos que the praticaram uma nova $\mathrm{R}$. W. a qual resultou ainda fortemente positiva $(++++)$. Applicaram-lhe tambem umas injecções cuja natureza ignora - provavelmente de acção especifica. Após esta temporada de ausencia, voltou á Polyclinica, onde continuámos com a nossa therapeutica. Dessa época em diante resolvemos, a conselho do nosso prezado mestre Dr. Eduardo Monteiro, variar de medicamento usando um composto de vanadio (tartaro vanadato de sodio). Assim procedemos, injectandiothe o conteudo de 25 empoullas de 2 cc. e de 0,15 cada uma, duas vezes por semana e, portanto, um total de 3,75 de tartaro vanaciato durante 3 mezes e meio. O resultado foi então surprehendente. O baço principiou a regredir "pari-passu" ao tratamento, com melhoras extraorcinarias do estado geral. A doente ganhava côres, engordava e alimentava-se com grande appetite. Foi quando realizámos o segundo exame de sangue, no que se refere aos elementos figurados e á dosagem da hemoglobina, afim de controllar os beneficios da therapeutica. O resultado foi, como já teferimos, satisfactorio. Entretanto, examinemos parallelamente a relação dos dois exames: No primeiro, os globulos vermelhos eram em numero de $3.000 .000 \mathrm{p} / \mathrm{mm} 3$, no segundo subiu para $3.880 .000 \mathrm{p} / \mathrm{mm} 3$. O numero de globulos brancos de 4.400 $\mathrm{p} / \mathrm{mm} 3$ que era, passou para $6.950 \mathrm{p} / \mathrm{mm}$. A dosagem da hemoglobina, que revelou antes $42 \%$, ao depois attingiu a cifra de 
$60 \%$. Como acabaes de vểr, o surto de anemia secundaria que a lesão do baço promovera, passava a regredir juntamente com o orgão. Nesta opportunidade, convidámos o Dr. Oscar Monteiro de Barros, a examinar a nossa paciente e manifestar o seu juizo critico a respeito do caso. A sua opinião foi-nos summamente favoravel, pois o Dr. Monteiro de Barros, poude verificar, como nós, que a glandula esplenica já regredira quasi completamente. Decorridos alguns dias, e não mais conseguimos surprehender o baço fóra de sua séde anathomica normal.

Neste estado a doente regressou a Leme, onde reside, munida de saude e indicações para continuar o tratamento especifico.

\section{DISCUSSÃO}

Dando inicio á discussão do caso em apreço, cumpre-nos frizar de ante-mão as dffficuldades extremas que ha de encontrar, seja quem fôr que se abalance a estabelecer um diagnostico preciso de lues terciaria do baço - e nós estamos longe de assim proceder. Quando cogitámos de uma tal hypothese, não foi mirando o brilho de uma jactancia futil e sim baseados, como vistes, em signaes e symptomas manifestamente insinuantes. Pois a entidade morbida que ora nos occupa, se, em determinadas circumstancias permitte uma differenciação satisfactoria relativamente a muitas das congeneres, noutras comtudo, tão difficil se torna e, digamos mesmo, quasi impossivel se, em nosso auxilio, não vier o soccorro de um exame directo, quer seja pela necropsia, quer pela esplenectomia como fim therapeutico ou, ainda, como succedeu com a nossa paciente, que se dê a cura real pelo tratamento especifico. Este ultimo facto foi, para nós, um dos maiores estimulos que motivou a divulgação do nosso trabalho.

\section{Diagnostico differencial}

Digamos alguma coisa acerca do diagnostico differencial. Primeiramente, vejamos se se trata de um baço hypertrophiado, ou duma formação de natureza differente. Ora, isto não padece duvidas, tal a sua localização topographica, seus limites, sua fórma, sua consistencia, seu bordo antero-superior e chanfradura caracteristicas, conforme relatámos quando do nosso exame clinico. Se abordámos o assumpto foi, unicamente, a titulo illustrativo. Apenas citaremos então estas causas: - São ellas, certas formações peritoniaes mal delimitadas; processos pancreaticos taés como: tumores, kystos, etc.; tumores da capsula supra-renal esquerda ou do proprio rim; hypertrophia do lobo esquerdo do figado: tumor do angulo collico esquerdo, do coíion descendente; tumores pel- 
vicos, etc.; fibroma do utero; kysto do ovario, etc. Superfluo seria, tambem, discutirmos as molestias infecciosas agudas como scjam: febre ty phoide, febres intermittentes, typho exanthematico, variola, escarlatina, febre de Malta, etc.; nas quaes a esplenomegalia surge apenas como signal accessorio.

lão se trata de um baço migrante, porque não ha ptóse da viscera. Antes, pelo contrario, o limite de massicez superior, sobe além do normal (setimo espaço inter-costal), com desapparecimento do espaço de Traube em ausencia de derrame pleural e pericardico.

Das esplenomegalias ditas primitivas, os exames de laboratorio permittem-nos excluir as seguintes hypotheses:

Tuberculose: Reacção de Mantoux ou prova da tuberculina - negativa.

Malaria: Pesquizas de hematozoarios no sangue, effectuadas em 3 opportunidades differentes - negativas todas.

Kysto hydatico: Reacção de Weinberg ou do desvio do complemento - negativa.

Enı relação ás outras esplenomegalias primitivas, tanto de crigem hematica quanto visceral, seria muito difficil separal-as da luetica. Só mesmo o criterio therapeutico nos dá margem a assim proceder. Portanto, não discutiremos os processos degenerativos do baço, o mal de Banti, o esplenogranuloma siderotico de Gamna, o linphosarcoma, o angiosarcoma, etc.; que só a necropsia com exame directo poderia esclarecer. Repetimos, comtudo, que qualquer hypothese que pudesse ser aventada, differente da luetica, não resistiria ao criterio therapeutico.

Quem encontra uma esplenomegalia como a nossa, mesmo que haja uma Wassermann francamente positiva, nem por isso єstá autorizado a formular, desde logo, um diagnostico etyologico seguro, de esplenomegalia luetica terciaria. Referindo-se á nossa paciente, aggrava ainda a situação, o facto da esplenomegalia pertencer a uma mulher já idosa (50 annos) com lues indubitavelmente adquirida, conforme vimos pela anamnése, pois, como sabeis, a frequencia das esplenomegalias syphiliticas é muito maior nos casos de lues hereditaria e nos individuos jovens. Attenda-se a que tambem não ha signaes cardiacos pathologicos nem lesões vasaes. O que se manifestou exteriormente foram, além do syphiloma inicial, os processos gommosos. Seria então uma gomma ou multiplas gommas esplenicas, ou tratar-se-ia de esplenite syphilitica? A occurrencia de qualquer uma destas nypotheses não diminuiria o valor da nossa observação, uma vez que ambas não 
inffirmariam o diagnostico etiologico, unico importante em o nosso caso. Entretanto afigura-se-nos mais provavel tratar-se de esplenite ao envez de gomma, dada a raridade maior deste ultimo processo em relação ao primeiro. Além disto, cumpre levar em consideração os outros caracteres com que a esplenomegalia se apresenta, taes como: Crescimento proporcional em todos os sentidos, superficie lisa, tamanho gigantesco, etc. Apezar de todas estas razões, nada ousamos affirmar relativamente á modalidade anathomo-patologica da lesão visceral.

Finalizando este nosso estudo, não nos podemos abster de dizer-vos o quanto nos surprehencieu o exito brilhante da therapeutica especifica. Não que tivessemos duvidas a respeito de sua efficiencia, mas, cumpre notar, não esperávamos uma tão prompta obediencia, por parte da esplenomegalia, aos medicamentos empregados. De todos os casos que tivemos conhecimento, através da litteratura, em nenhum vimos assignalada a regressão total do baço doente.

As observações que temos manuseado e que foram feitas nesse sentido, limitam-se a relatar regressões parciaes, umas mais intensas que as outras, porém, todas ultrapassando os limites que a semiologia nos ensina como séde normal dla viscera. Nestas condições, o nosso caso - ousamos affirmar conscienciosamente foi uma excepção á regra. Aos poucos, a glandula esplenica, voltou ás suas dimensões anatomicas normaes. Foi um resultado brilhante do tratamento especifico. Como explicar este facto? Não ousamos fazel-o com segurança. Aos collegas pedimos venia para formular a mesma pergunta. Seria tão suave o processo regenerativo do orgã̃o, que não deixasse traços após si? Pura hypothese. $O$ que permanece verdadeiro é que o baço, após ter attingido as proporções gigantescas que já conheceis, regrediu completamente. Fica portanto aqui a observação. 
